\title{
Cardiovascular disease in cancer survivors
}

\author{
Tochi M Okwuosa, ${ }^{1}$ Sarah Anzevino, ${ }^{2}$ Ruta Rao ${ }^{2}$
}

${ }^{1}$ Division of Cardiology, Rush University Medical Center, Chicago, Illinois, USA ${ }^{2}$ Division of Hematology, Oncology and Cell Therapy, Rush University Medical Center, Chicago, Illinois, USA

\section{Correspondence to} Dr Tochi M Okwuosa, CardioOncology Services, Rush University Medical Center, 1717 West Congress Parkway, Kellogg Bldg, Suite 328, Chicago, IL 60612, USA; tokwuosa@rush.edu

Received 2 August 2016 Revised 30 August 2016 Accepted 15 September 2016 Published Online First 8 October 2016

\section{CrossMark}

To cite: Okwuosa TM, Anzevino S, Rao R. Postgrad Med J 2017:93:82-90.

\section{ABSTRACT}

Certain cancer therapies, including radiation therapy and some types of chemotherapies, are associated with increased risk of cardiovascular disease (CVD) and events. Some of these effects such as those presented by anthracyclines, radiation therapy, cisplatin, as well as those presented by hormone therapy for breast cancerusually taken for many years for some breast and prostate cancers-are long-lasting and associated with cardiovascular events risk more than 20 years after cancer treatment. Cardiovascular testing, diagnostic assessment of suspected cardiovascular symptomatology, as well as laboratory tests for CVD risk factors are imperative. The early recognition and treatment of CVD processes that arise in survivorship years is pivotal, with specific attention to some CVD processes with specific suggested treatment modalities. Preventive measures include adequate screening, the use of medications such as ACE inhibitors/angiotensin receptor blockers and/or beta blockers, statin therapy and aspirin in persons who warrant these medications, as well as therapeutic lifestyle modifications such as exercise/physical activity, weight loss and appropriate diet for a healthy lifestyle. Periodic follow-up with a good primary care physician who understands the risks associated with cancer therapy is important, and referral to onco-cardiology for further management of cardiovascular risk in these survivors is based on a patient's cardiovascular risk level and the type, amount and duration of cancer therapies received during the patient's lifetime.

\section{INTRODUCTION}

Heart disease and cancer are the first and second leading causes of death in the USA and the world overall. Nonetheless, there have been dramatic improvements in cancer therapies, which have led to significant improvements in cancer survival such that in 2014, the American Cancer Society reported that there were over 14 million cancer survivors in the USA. ${ }^{1}$ That number is projected to increase to close to 19 million by year $2024 .^{1} \mathrm{Next}$ to cancer recurrence or progression and second malignancies, the leading cause of death in cancer survivors is cardiovascular diseases (CVDs) due to the intense oncological treatment which these patients have received. ${ }^{2-5}$ Furthermore, the risk of cardiovascular morbidity is shown to be higher than that of tumour recurrence in these cancer survivors. ${ }^{67}$ Many decades after diagnosis, cancer survivors had 15 -fold increased rates of congestive heart failure (CHF), 10-fold higher rates of CVD, 9-fold higher rates of stroke and higher incidence of cardiovascular risk factors, compared with controls. ${ }^{8} 9$ Cancer-related cardiovascular morbidity and mortality is attributed to cancer therapy with chemotherapies and radiation therapies (tables 1 and 2, respectively), and risks may persist up to 45 years after therapy. ${ }^{10}$

This review aims to focus on the particular cancer therapies associated with CVD in cancer survivors, their initial diagnosis and management, as well as measures to prevent this risk in survivors in order to best ensure cardiovascular longevity after cancer treatment.

\section{DISCUSSION}

A number of cancer therapies have long-term cardiovascular sequelae, leading to higher rates of cardiovascular morbidity and mortality in cancer survivors. These include chemotherapies such as doxorubicin and cisplatin, hormone therapiesusually administered long term for a total duration of 5-10 years in the case of breast and prostate cancers, as well as radiation therapy. The anticipated long-term cardiovascular issues in this population include cardiomyopathy/heart failure, hypertension, dysrhythmias and autonomic dysfunction, valvular heart disease, coronary artery disease $(\mathrm{CAD})$ and pericardial diseases.

\section{CVD associated with chemotherapy, hormone and targeted therapies in cancer survivors Cardiomyopathy/heart failure}

Various chemotherapeutic agents have been implicated in causing cardiomyopathy with both systolic and diastolic dysfunction, which could eventually progress to clinical heart failure (table 1). The most notable chemotherapeutic class of drugs implicated in this process is anthracyclines (particularly doxorubicin). Anthracyclines are particularly known to increase the risk of cardiomyopathy with systolic dysfunction and heart failure by generation of free radicals, leading to cardiac cell damage. ${ }^{11}$ As such, more than $50 \%$ of all patients exposed to anthracycline chemotherapy will show some degree of cardiac dysfunction 10-20 years after chemotherapy and 5\% will develop overt heart failure with up to $60 \%$ mortality. ${ }^{12}$ The risk of cardiomyopathy associated with anthracyclines varies based on a variety of factors, including the type of anthracycline (doxorubicin carries higher risk than epirubicin or liposomal doxorubicin), the route and speed of administration, concomitant radiation therapy or other cardiotoxic chemotherapy, concomitant cardiac risk factors, old and young age and female sex. ${ }^{14}$ For cancer survivors, it is noteworthy that the risk of anthracycline-induced cardiomyopathy exhibits a bimodal age distribution, with lower doses of anthracyclines affecting older as well as younger patients, ${ }^{11}$ with up to $32 \%$ of patients in the younger age distribution presenting with left ventricular dysfunction at some point after anthracycline administration. ${ }^{15}$ 
Table 1 Chemotherapeutic classes and associations with short-term and long-term cardiotoxicities, diagnostic modalities and management/ prevention

\begin{tabular}{|c|c|c|c|}
\hline Chemotherapy cardiotoxicity & $\begin{array}{l}\text { Major culprit chemotherapeutic classes } \\
\text { (incidence) }\end{array}$ & Diagnostic methodologies & Management/prevention \\
\hline $\begin{array}{l}\text { Cardiomyopathy (with systolic and/or } \\
\text { diastolic dysfunction) }\end{array}$ & $\begin{array}{l}\text { Anthracyclines* } \\
\text { Monoclonal antibodies* } \\
\text { VSP inhibitors* } \\
\text { Alkylating agents } \\
\text { Antimicrotubule agents } \\
\text { Antimetabolites } \\
\text { Proteasome inhibitors* }\end{array}$ & $\begin{array}{l}\text { Echocardiography } \\
\text { Myocardial strain imaging by } \\
\text { echo } \\
\text { Cardiac MRI } \\
\text { MUGA/RNA } \\
\text { Biomarkers: troponin, BNP, } \\
\text { newer biomarkers } ¥ \\
\text { Possible role for genetics }\end{array}$ & $\begin{array}{l}\text { ACE-I/ARB } \\
\text { Beta blockers } \\
\text { Deferoxaminef } \\
\text { Possible role for statins } \\
\text { Possible role for ranolazine } \\
\text { Serial LVEF/biomarker monitoring } \\
\text { Discontinue chemotherapy, then reinstitute } \\
\text { with LVEF recovery } \\
\text { Long-term consideration for ICD and } \\
\text { possible heart transplantation }\end{array}$ \\
\hline Ischaemia & $\begin{array}{l}\text { Antimetabolites (vasospasm) } \\
\text { VSP_inhibitor TKIs (Mab and Smol)_- } \\
\text { arterial thrombosis } \\
\text { Antimicrotubule agents (arterial } \\
\text { thrombosis) } \\
\text { Alkylating agents* } \\
\text { Angiogenesis inhibitor-arterial } \\
\text { thrombosis }\end{array}$ & $\begin{array}{l}\text { ECG } \\
\text { Troponin } \\
\text { Stress test§ } \\
\text { Coronary angiography } \\
\text { Cardiac MRI }\end{array}$ & $\begin{array}{l}\text { Nitrates for coronary spasms } \\
\text { Aspirin for thrombosis risk } \\
\text { Limited data for other antianginal agents }\end{array}$ \\
\hline Thrombosis & $\begin{array}{l}\text { Alkylating agents-venous } \\
\text { Angiogenesis inhibitor-arterial } \\
\text { VSP inhibitors- } \\
\text { venous and arterial } \\
\text { Histone deacetylase inhibitors - venous } \\
\text { Immunomodulators-arterial } \\
\text { Hormonal therapy (tamoxifen) - } \\
\text { arterial/venoust }\end{array}$ & $\begin{array}{l}\text { Doppler ultrasound } \\
\text { CT angiography } \\
\text { Other concern as for ischaemia } \\
\text { above }\end{array}$ & $\begin{array}{l}\text { Unfractionated heparin } \\
\text { Low molecular weight heparin } \\
\text { Fondapariux }\end{array}$ \\
\hline Hypertension & $\begin{array}{l}\text { VSP inhibitors/targeted therapies* } \\
\text { VEGF trap } \\
\text { Alkylating agents* }\end{array}$ & $\begin{array}{l}\text { On-site blood pressure checks } \\
\text { Ambulatory blood pressure } \\
\text { monitoring }\end{array}$ & $\begin{array}{l}\text { Amlodipine } \\
\text { ACE-I/ARB } \\
\text { Other antihypertensive regimens as } \\
\text { third-line agents }\end{array}$ \\
\hline Hypotension & $\begin{array}{l}\text { Interferons } \\
\text { Interleukins } \\
\text { All-trans retinoic acid (differentiation } \\
\text { syndrome) }\end{array}$ & $\begin{array}{l}\text { On-site blood pressure checks } \\
\text { Ambulatory blood pressure } \\
\text { monitoring }\end{array}$ & $\begin{array}{l}\text { Intravenous fluids } \\
\text { Midodrine (if normal LVEF) } \\
\text { Discontinue chemotherapy if in shock, then } \\
\text { reinstitute when stable }\end{array}$ \\
\hline Dysrhythmias & $\begin{array}{l}\text { Interleukins } \\
\text { Interferons } \\
\text { Angiogenesis inhibitors (bradycardia) } \\
\text { Antimicrotubule agents (bradycardia) } \\
\text { Histone deacetylase inhibitors } \\
\text { - Aron-VSP inhibitor small molecule TKIs } \\
\text { Arsenic trioxide }\end{array}$ & $\begin{array}{l}\text { ECG } \\
\text { Telemetry }\end{array}$ & $\begin{array}{l}\text { Beta blockers } \\
\text { Propafenone } \\
\text { Anticoagulation with low molecular weight } \\
\text { heparin }\end{array}$ \\
\hline QTc prolongation & $\begin{array}{l}\text { Arsenic trioxide } \\
\text { Histone deacetylase inhibitors } \\
\text { Small molecule TKIs }\end{array}$ & $\rightarrow \mathrm{ECG}$ & $\begin{array}{l}\text { Replete electrolytes (K/Mg) } \\
\text { Serial ECG monitoring } \\
\text { Discontinue other QTc prolonging drugs, } \\
\text { where possible } \\
\text { Discontinue chemotherapy agent, if } \\
\text { significant risk of torsades }\end{array}$ \\
\hline Pericardial disease & $\begin{array}{l}\text { Busulfan* } \\
\text { Non-VSP inhibitor small molecule TKIs }\end{array}$ & $\begin{array}{l}\text { Echocardiography } \\
\text { Cardiac MRI } \\
\text { Cardiac CT }\end{array}$ & $\begin{array}{l}\text { Pericardiocentesis } \\
\text { Pericardial window } \\
\text { Pericardial stripping (with constriction) } \\
\text { Colchicine (if no interaction with } \\
\text { chemotherapy) } \\
\text { NSAIDs (if normal blood pressure and } \\
\text { LVEF) }\end{array}$ \\
\hline
\end{tabular}

${ }^{*}$ Associated with long-term cardiotoxicity; does not necessarily apply to all agents within each mentioned drug class.

tLong-term toxicity as a function of protracted use.

¥Newer biomarkers with possible future promise include: serum galectin-3, ST-2, glycogen phosphorylase BB (GPBB), heart-type fatty acid-binding protein (H-FABP) and high-sensitivity $\mathrm{C}$ reactive protein (hs-CRP). ${ }^{81-84}$

$\S$ Stress test by Single-photon emission computed tomography (SPECT)-myocardial perfusion imaging, Fludeoxyglucose- (FDG)-Positron Emission Tomography (PET) scan and stress

echocardiography. Of questionable utility, particularly if ischaemia is related to coronary vasospasm.

IDeferoxamine particularly cardioprotective against anthracyclines.

Concern for chemotherapy-drug interactions with drugs that affect the cytochrome P-450 system (diltiazem, digoxin, amiodarone), as well as other QTc prolonging antiarrhythmics (flecainide, ibutilide, dofetilide, sotalol). ${ }^{85}$

Amlodipine is a very effective first-line agent for TKI-induced hypertension and proteinuria; ACE-I/ARBs are also useful (in addition to amlodipine) for proteinuria associated with these agents.

SARB, angiotensin receptor blocker; BNP, brain natriuretic peptide; ICD, implantable cardioverter defibrillator; LVEF, left ventricular ejection fraction; MUGA, multigated acquisition scan; NSAIDs, non-steroidal anti-inflammatory drugs, RNA, radionuclide angiography, TKI, tyrosine kinase inhibitor; VSP, vascular endothelial growth factor (VEGF) signalling pathway. 
Trastuzumab is a monoclonal antibody which targets the Human Epidermal Growth Factor Receptor-2 (HER-2) receptor. The incidence of trastuzumab-associated cardiac dysfunction is about $5-10 \%$ with $2-3 \%$ incidence of clinical heart failure. However, used in combination with doxorubicin, trastuzumab leads to $>7$-fold increased risk of heart failure ${ }^{16}$ Unlike anthracyclines which lead to type I irreversible myocyte destruction and cardiac dysfunction, trastuzumab cardiac dysfunction is not dose related and is mostly known to lead to reversible ErbB2 signalling-mediated type II cardiac dysfunction without ultrastructural changes. ${ }^{17}$ On the other hand, more recent studies have suggested that cardiotoxicity associated with trastuzumab progressively increased during 3-5 years after the end of treatment and can persist many years after the conclusion of the therapy, thus strongly suggesting that it is not always reversible as initially proposed. ${ }^{18} 19$

The risk of heart failure with reduced systolic function has been reported to be as high as $4 \%$ with bevacizumab, a monoclonal antibody which inhibits vascular endothelial growth factor (VEGF) A. ${ }^{20}$ In this case, concurrent use of taxanes, capecitabine and anthracyclines does not significantly increase the incidence or relative risk of heart failure. ${ }^{20}$ However, prior use of anthracyclines may cause the left ventricular ejection fraction (LVEF) to be decreased at baseline. In a randomised controlled trial of capecitabine in combination with bevacizumab for treatment of metastatic breast cancer, $50 \%$ of the patients who developed $\mathrm{CHF} /$ cardiomyopathy had a baseline LVEF of $<50 \%$ and all of these patients had previously received anthracyclines. ${ }^{21}$

Other class of drugs associated with long-term heart failure in cancer survivors includes VEGF signalling pathway (VSP) inhibitors such as sunitinib and sorafenib. Sunitinib has been associated with reduced LVEF with an incidence of 4.1. ${ }^{22} 23$ However, the incidence of LV dysfunction is variable among different studies varying from as low as $0 \%$ to as high as $28 \% .^{23-}$ 25 A small study of patients treated with sunitinib showed a mean reduction of $5 \%$ in $\mathrm{LVEF}$, with an initial $2 \%$ reduction from baseline followed by $1-5 \%$ reduction per cycle in subsequent cycles. ${ }^{25}$ Furthermore, the incidence of LV dysfunction in patients on sorafenib is $4.7 \%$, without any noted difference between sorafenib and placebo. ${ }^{26}$ On the other hand, when compared with other VEGF inhibitors, pazopanib has a relatively higher incidence of all grades of heart failure at $6.1 \%,{ }^{27}$ while vandetanib and ramucirumab have the lowest incidences of heart failure in this class of drugs. ${ }^{27-30}$ Although some studies suggest complete recovery after treatment, ${ }^{31}$ the total reversibility of heart failure associated with these VEGF inhibitors has been called into question in other studies. ${ }^{32-34}$ As such, patients with cancer having received these therapies may have to live with LV dysfunction as survivors.

\section{CAD and cardiovascular events}

The risk of cardiovascular events is higher years after cisplatin (a potent alkylating agent) therapy, is mostly related to elevated risk of cardiovascular risk factors and endothelial dysfunction associated with the drug and the fact that cisplatin can be detected in the blood up to 20 years after treatment. ${ }^{35}$ Delayed cardiovascular toxicity, including acute myocardial infarction, and cerebrovascular events have been reported with cisplatin. ${ }^{36}$ Similarly, a study by Haugnes et al, ${ }^{37}$ showed 5.7-fold higher risk of CAD and 3.1-fold higher risk of myocardial infarction with cisplatin-based regimens, compared with surgery alone in a median observation time of 19 years (range: 13-28 years).

Some hormone therapies usually taken for up to 5-10 years after initial breast cancer treatment are also associated with elevated cardiovascular events risk. A 2013 meta-analysis of randomised trials of third-generation aromatase inhibitors as alternatives to tamoxifen involved $\sim 34000$ patients and showed higher risk of cardiovascular events $(\mathrm{OR}=1.20 ; \mathrm{p}=0.030)$, compared with tamoxifen monotherapy. ${ }^{38}$ In the same study, the absolute risk of cardiovascular events with either drug was low at $4.2 \%$ with aromatase inhibitors and $3.4 \%$ with tamoxifen. On the other hand, tamoxifen and raloxifene caused a doubling in the rate of deep vein thrombosis and pulmonary embolism compared with placebo (relative risk $1.9(1.4-2.6) ; \mathrm{p}<0.0001$ in the prevention trials). ${ }^{39}$ The findings were similar in a study of 5408 hysterectomised women randomly assigned to tamoxifen versus placebo. $^{40}$ On the other side, men with baseline history of CAD-induced $\mathrm{CHF}$ or myocardial infarction treated long term with androgen deprivation therapy for prostate cancer had excess risk of cardiovascular events and mortality. ${ }^{41} 42$

\section{Hypertension}

In addition to a threefold increased risk of LV dysfunction and heart failure, the monoclonal antibody bevacizumab exhibited a fivefold increased risk of hypertension, while causing a 30\% risk reduction in progression-free survival events in patients with HER-2-negative metastatic breast cancer. $^{43}$ Many tyrosine kinase inhibitors (TKIs)/ VSP inhibitors also cause hypertension, which is a common mechanism by which VSP inhibitors can cause long-term consequences, including renal dysfunction, myocardial ischaemia/infarction, strokes, as well as LV dysfunction with possible heart failure. ${ }^{44}$ All of these issues can persist for years after treatment has ended. Furthermore, hypertension is a late adverse effect of cisplatin in about $20-50 \%$ of patients post-combination chemotherapy. ${ }^{46} 47$ Cisplatin causes vascular endothelial damage with significant oxidative stress and vasoconstriction associated with VEGF pathways, thus leading to long-term hypertension. It also carries the risk of acute kidney injury with proximal tubular injury, oxidative stress, inflammation and vascular injury in the kidney, which could then lead to hypertension long term. ${ }^{48}$ Exemestane, an aromatase inhibitor for treatment of hormone receptor-positive breast cancer, is also associated with higher long-term risk of hyperten$\operatorname{sion}^{49}$ and subsequent cardiovascular events.

\section{Metabolic syndrome and cardiovascular risk factors}

Cancer survivors overall have a greater risk of cardiovascular risk factors. ${ }^{50}$ Indeed, the prevalence of cardiovascular risk factors was notably higher in cancer survivors compared with their siblings in the Childhood Cancer Survivor Study of 8599 survivors (52\% male) and 2936 siblings (46\% male). In this study, survivors were more likely to take medications for hypertension (OR 1.9 95\% CI 1.6 to 2.2), dyslipidaemia (OR 1.6 95\% CI 1.3 to 2.0 ) and diabetes (OR $1.795 \%$ CI 1.2 to 2.3 ), compared with their siblings. ${ }^{51}$

Cancer drugs also increase the risk of cardiovascular risk factors and subsequent CVD. In a population of patients with testicular cancer, cisplatin was associated with higher rates of hypertension, dyslipidaemia with hypertriglyceridaemia, elevated Body Mass Index (BMI) and insulin resistance compared with control patients with the same disease treated surgically without chemotherapy. ${ }^{46} 5253$ In addition, 5-10-year duration of aromatase inhibitor endocrine therapy for hormone receptorpositive breast cancer treatment is associated with dyslipidaemia, particularly lowered High Density Lipoprotein (HDL) cholesterol with long-term cardiovascular consequences. In the Arimidex, Tamoxifen, Alone or in Combination Trial (ATAC) study, anastrozole use was associated with higher incidence of 
dyslipidaemia; ${ }^{54}$ with similar findings for letrozole in the Breast International Group Trial (BIG) 1-98 trial. $^{55}$

\section{Pericardial disease}

Similar to radiation therapy, there have been cases of pericardial and endomyocardial fibrosis linked to busulfan therapy usually exceeding $600 \mathrm{mg}$ and occurring 4-9 years after treatment. ${ }^{56}$

\section{CVD associated with radiation therapy in cancer survivors}

Radiation therapy has been shown to significantly reduce rates of cancer recurrence and mortality due to cancer, but is associated with irradiation of surrounding organs, other than the area of tumour. Chest wall radiation as seen in patients with lung cancer, lymphoma, oesophageal cancer and breast cancer is associated with irradiation to the heart, especially when confined to the left chest wall as in left-sided breast cancer. ${ }^{57}{ }^{58}$ Radiation-induced heart disease which occurs in up to $50 \%$ of patients post-chest wall radiation therapy includes a myriad of cardiac abnormalities, including valvular heart disease, pericardial disease (pericarditis, pericardial effusion and constriction), conduction disturbances and arrhythmias and cardiomyopathy, which can occur up to 20-30 years after radiation therapy (table 2). ${ }^{59}$

Autonomic dysfunction is a cardiovascular sequelae of radiation therapy that has more recently come into recognition. ${ }^{60} \mathrm{In}$ their study of 263 Hodgkin lymphoma survivors referred for stress testing at a median interval of 19 years post-radiation therapy (range: 1-55 years), Groarke et al showed elevated resting heart rate and heart rate recovery (HRR) in a multivariate analysis (ORs: 3.96 and 2.52, respectively), which worsened with time from radiation. They also showed that abnormal HRR was associated with all-cause mortality (age-adjusted HR: 4.60). ${ }^{60}$

$\mathrm{CAD}$ is another major cardiovascular problem associated with radiation therapy. Higher doses of radiation were associated with increased risk of major coronary events in women treated for breast cancer. ${ }^{61}$ This risk began within the first 5 years after radiation therapy and continued until the third decade afterwards. Of note, this particular study was based on older radiation techniques involving electron beam radiation therapy with higher radiation doses.

By the turn of the 21st century, most institutions adopted newer radiation techniques (including deep inspiration breath hold (DIBH), gating, accelerated partial breast irradiation and the use of modern 3D planning) with less radiation dosage. Nonetheless, a Surveillance, Epidemiology and End Results Program (SEER) database study of 29102 patients diagnosed with breast cancer from 2000 to 2009 showed a small increase in the risk of percutaneous coronary intervention (PCI) after radiation therapy: $5.5 \%$ versus $4.5 \%$ for left-sided breast cancer versus right-sided breast cancer. In those who underwent PCI, left-sided breast cancer carried significantly increased risk of cardiac mortality with a subdistribution HR of 2.02 (95\% CI 1.23 to 3.34 ), compared with right-sided breast cancer. ${ }^{62}$ Of note, prior studies have shown right-sided breast cancer also carries significantly increased but smaller risk of cardiovascular events compared with left-sided breast cancer. ${ }^{57}$ However, the incidence and prevalence of heart disease with these newer radiation therapy techniques are unknown.

\section{Presentation and diagnosis}

Typical cardiovascular concerns in the survivorship years include left ventricular systolic and diastolic dysfunction, CAD, tachyarrhythmia or bradycardia, valvular heart disease, pericardial disease (including effusion and constriction) and carotid artery disease, all with associated cardiovascular events risk and subsequent morbidity and/or mortality. As such, cancer survivors and their clinicians should be watchful for cardiovascular symptoms (figure 1). Cardiovascular risk factors, such as hypertension, diabetes mellitus and dyslipidaemia, are also of importance in the survivorship years as they could lead to overt CVD and associated complications (the risks of which are magnified after cancer therapy), in addition to systemic manifestations with related comorbidities. As such, the utility of establishing good primary care at the very least, with regular follow-up visits and laboratory testing with or without imaging in the cancer survivor, cannot be overemphasised. Annual ECGs should be obtained, along with annual blood tests to assess renal function and electrolytes, liver and thyroid functions and glucose/haemoglobin A1c, lipid profile, blood haemoglobin and haematocrit levels as useful initial assessments.

Some patient groups with prior or higher future risk of cardiovascular events require regular follow-up visits with a cardiologist-preferably an onco-cardiologist well versed in cardiovascular expectations relating to cancer therapies. For cardiovascular imaging studies, the echocardiography consensus statement recommends evaluation based on signs and symptoms as stated above, and a surveillance echocardiogram with strain imaging 6 months post-anthracycline therapy, then beginning at 5 years after cardiotoxic cancer therapies in high-risk patients, 10 years otherwise; and functional non-invasive stress testing within 5-10 years of completion of chest radiation therapy. ${ }^{63}$ It is noteworthy that the study by Cardinale et $a l,{ }^{64}$ showed that $98 \%$ of cardiotoxicities associated with anthracycline therapies occurred within the first year. As such, screening with echocardiogram with myocardial strain assessment 12 months after completion of anthracycline regimen seems reasonable. Speckle tracking echocardiography for detection of LV myocardial strain is a novel cardiac imaging technique assessed by echocardiography, which has been shown to be a very specific predictor of cardiac dysfunction in patients with cancer receiving chemotherapy. ${ }^{65}{ }^{66}$ Echocardiography in this setting should assess for pericardial disease, LV or right ventricular dysfunction and/or valvular heart disease. Of note, inducible perfusion abnormalities on SPECT perfusion imaging (or lack thereof) are not always correlated with the presence or absence of CAD. ${ }^{67}$ The role of the inexpensive and easily accessible coronary artery calcium CT and scoring, as well as coronary CT angiography in screening for radiation-induced CAD, is of utmost interest.

Brain natriuretic peptide and troponin as cardiac biomarkers have shown useful predictability for cardiotoxicity during and around the time of chemotherapy, but their use as predictors of cardiac disease in cancer survivors is yet to be defined.

\section{Treatment of CVD in cancer survivors}

Many of the treatment modalities for various CVDs in this population are as for that of the general population. Nonetheless, a number of major issues are worthy of note regarding the treatment of CVD among cancer survivors.

There is a small window of opportunity that exists in the treatment of anthracycline-related cardiomyopathy, after which the chances of full LVEF recovery are much reduced. In the study by Cardinale et $a l^{68}$ the possibility of full LVEF recovery steadily decreased with time and was $0 \%$ if heart failure therapy was initiated 6 months after the end of chemotherapy among patients who developed heart failure after anthracycline-based chemotherapy. As such, close monitoring with prompt recognition and institution of heart failure therapies such as ACE inhibitors and beta blockers is necessary to counteract the lifelong risk of heart failure in this population. 
Table 2 Long-term radiation-induced heart disease, diagnostic modalities and management

\begin{tabular}{|c|c|c|c|}
\hline Cardiac effects (prevalence) & Description & Screening/diagnosis & Management \\
\hline $\begin{array}{l}\text { Pericardial disease (6-30\%) } \\
\text { Pericarditis (acute or chronic) } \\
\text { Pericardial effusion } \\
\text { - Pericardial constriction }\end{array}$ & $\begin{array}{l}\text { Most common manifestation of radiation-induced heart disease and a } \\
\text { diagnosis of exclusion. Occurs due to fibrinous exudates to the pericardial } \\
\text { surface, fibrotic changes to the parietal pericardium. Acute pericarditis is often } \\
\text { self-limiting. Chronic pericarditis is often effusive-constrictive }\end{array}$ & $\begin{array}{l}\text { Diagnosis of exclusion after other causes } \\
\text { of pericardial disease have been ruled } \\
\text { out } \\
\text { Echocardiogram } \\
\text { Cardiac MRI } \\
\text { Cardiac CT }\end{array}$ & $\begin{array}{l}\text { Anti-inflammatory drugs for pericarditis } \\
\text { Pericardiocentesis for large effusions or tamponade } \\
\text { Pericardial window for recurrent pericardial effusions } \\
\text { Pericardial stripping for constrictive pericarditis }\end{array}$ \\
\hline $\begin{array}{l}\text { Coronary artery disease (up to } \\
85 \% \text { ) } \\
\text { Microvascular CAD } \\
\text { Macrovascular CAD }\end{array}$ & $\begin{array}{l}\text { Due to capillary network/epicardial coronary arteries damage and sustained } \\
\text { inflammation via NF-KB. Usually occurs } \geq 10 \text { years post-radiation therapy. } \\
\text { Involves the LM, sctial LAD and RCA. Lesions are longer, smoother, concentric } \\
\text { and tubular. Incidence increased by standard CV risk factors }\end{array}$ & $\begin{array}{l}\text { Stress echocardiography (could also } \\
\text { screen for other causes of RIHD, other } \\
\text { than CAD) or stress perfusion imaging } \\
\text { Cardiac CTA } \\
\text { Possible role for coronary calcium } \\
\text { screening }\end{array}$ & $\begin{array}{l}\text { As for CAD in patients not treated with radiation: medical therapy, } \\
\text { percutaneous coronary angioplasty and coronary artery bypass graft } \\
\text { (challenging surgical due to fibrosis of pericardium and } \\
\text { mediastinum) } \\
\text { Aggressive CV risk factor modification }\end{array}$ \\
\hline $\begin{array}{l}\text { Valvular heart disease } \\
\text { At } 10 \text { years }(26 \% \mathrm{Al}, 39 \% \mathrm{MR} \text {, } \\
16 \% \text { TR and } 7 \% \mathrm{PI}) \\
\text { At } 20 \text { years: }(60 \% \mathrm{Al}(16 \% \\
\text { Aortic Stenosis (AS)), } 52 \% \mathrm{MR} \text {, } \\
26 \% \text { TR and } 12 \% \mathrm{PI})\end{array}$ & $\begin{array}{l}\text { The mean time interval of } 12 \text { years. Diffuse fibrosis of the valvular cusps or } \\
\text { leaflets, with or without calcification; no post-inflammatory changes noted. } \\
\text { Left-sided valves }>\text { right-sided valves. Initial regurgitation related to valve } \\
\text { retraction }>\text { later stenosis related to thickening/calcification }\end{array}$ & $\begin{array}{l}\text { Echocardiogram } \\
\text { Cardiac MRI }\end{array}$ & $\begin{array}{l}\text { Serial monitoring with timing of surgery as in ACCIAHA guidelines } \\
\text { Valve replacement is preferred over valve repair which is associated } \\
\text { with worsened valve disease and heart failure } \\
\text { Consider TAVR, if mediastinum and cardiac anatomy is not } \\
\text { amenable to open heart surgery }\end{array}$ \\
\hline $\begin{array}{l}\text { Conduction system abnormalities } \\
\text { A-V nodal block (including } \\
\text { high-degree block) } \\
\text { Bundle branch block (RBBB > } \\
\text { than LBBB) } \\
\text { Fascicular block } \\
\text { Tachycardias } \\
\text { Prolonged QTC }\end{array}$ & $\begin{array}{l}\text { Not very common. Tachycardias can be persistent and is usually a result of } \\
\text { autonomic dysfunction, similar to denervated hearts. Persistent tachycardia } \\
\text { could increase the risk of tachycardia-induced cardiomyopathy }\end{array}$ & $\begin{array}{l}\text { ECG } \\
\text { Telemetry/ambulatory Holter monitor }\end{array}$ & $\begin{array}{l}\text { Permanent pacemaker as indicated for high-degree A-V block } \\
\text { ICD as indicated for life-threatening arrhythmia, sudden death or } \\
\text { secondary prevention } \\
\text { Consider subpectoral approach for device implantation, if there is } \\
\text { subcutaneous involvement of thoracic radiation }\end{array}$ \\
\hline $\begin{array}{l}\text { Cardiomyopathy } \\
\text { - Diastolic dysfunction >systolic } \\
\text { dysfunction } \\
\text { - Right ventricle >left ventricle }\end{array}$ & $\begin{array}{l}\text { Due to increased fibrosis in all three layers of the ventricular walls } \\
\text { (epicardium, myocardium and endocardium). May lead to restrictive } \\
\text { cardiomyopathy and rarely to systolic dysfunction. In addition, fibrosis of the } \\
\text { right ventricle is usually more extensive than of the left ventricle }\end{array}$ & $\begin{array}{l}\text { Echocardiogram } \\
\text { Cardiac MRI } \\
\text { Possible role for biomarkers (BNP, } \\
\text { troponin) }\end{array}$ & $\begin{array}{l}\text { Slow upward titration of ACE-I, beta blockade and aldosterone } \\
\text { inhibitors in patients with reduced LV systolic function } \\
\text { Optimise risk factors for diastolic dysfunction } \\
\text { Exercise training } \\
\text { Inotropic support, VAD and heart transplantation, as indicated }\end{array}$ \\
\hline \multicolumn{4}{|c|}{ 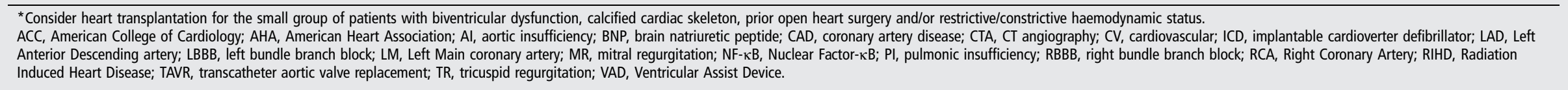 } \\
\hline
\end{tabular}




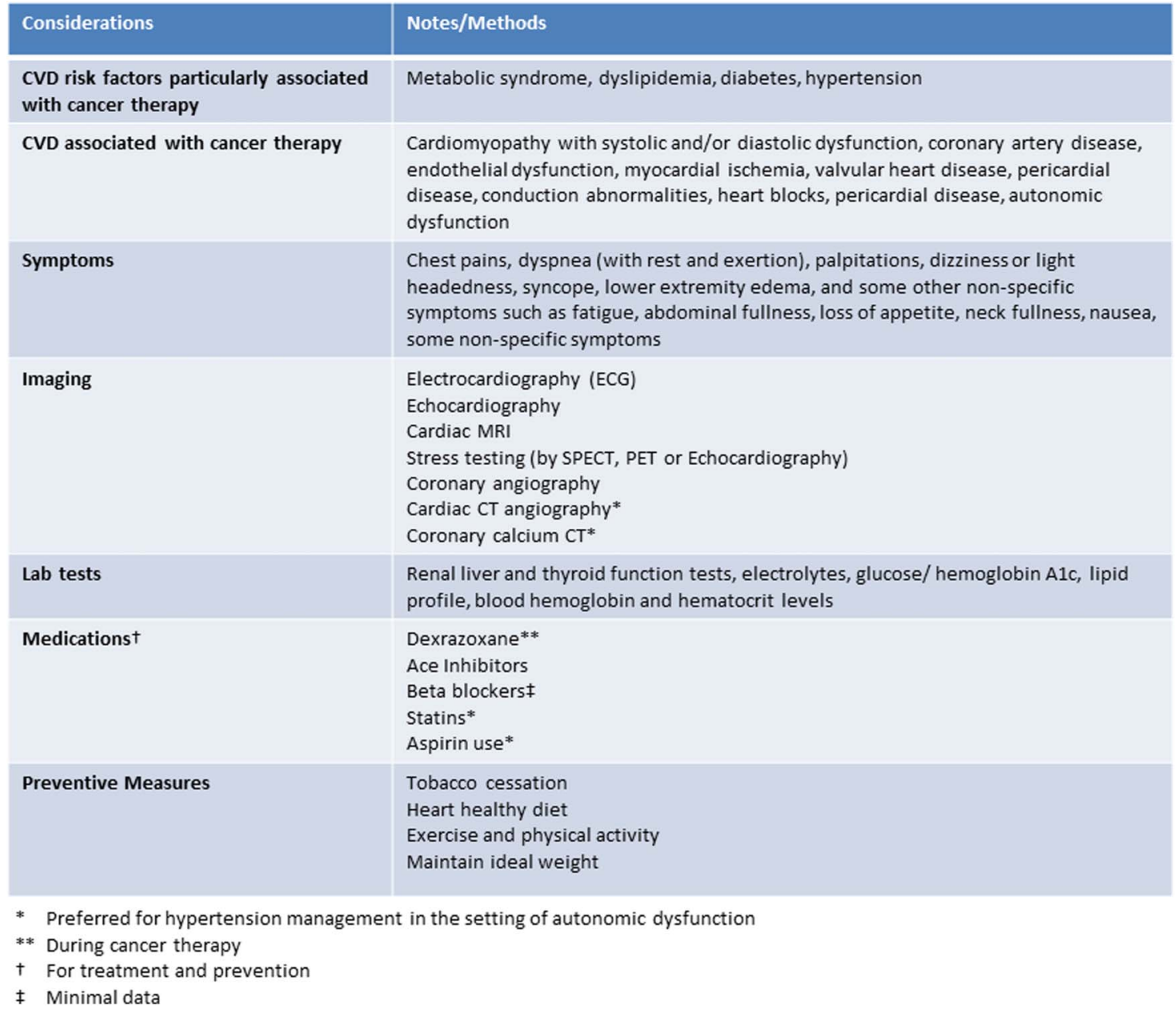

Figure 1 Considerations for assessment, management and prevention of chemotherapy-induced cardiovascular disease (CVD) in cancer survivors.

Another treatment matter worth noting is that the cancer therapeutic agents such as bevacizumab and TKIs administered for extended periods of time, as well as cisplatin that causes lifelong risk of hypertension; do so by causing endothelial dysfunction and vascular stiffness through already described mechanisms. The endpoint is a decrease in Nitric Oxide (NO) levels leading to systemic vasoconstriction and blood pressure elevation. ${ }^{69}$ As such, agents that stimulate NO production (such as nitrates) or those that counteract vascular stiffness (such as dihydropyridine calcium channel blockers) might be more useful in adequately controlling blood pressures in this population, ${ }^{70}{ }^{71}$ compared with other antihypertensive medications.

Radiation-induced valvular heart disease is yet another treatment-related affair which the treating physician should be aware of in cancer survivors. These can occur within the first 5 years, up to the third decade post-radiation therapy. ${ }^{61}$ The mechanism of radiation-induced heart disease is an inflammatory process $^{72}$ that causes acute upregulation of proinflammatory cytokines and adhesion molecules in endothelium (comprised in cardiac valves and vessels), which then recruits inflammatory cells to sites of endothelial injury. Furthermore, late effects of radiation therapy are caused by ionisation of water molecules, with radiation-induced chronic free radical production. As such, in patients post-chest wall radiation therapy who require heart valve replacement, it is generally advisable to consider the use of mechanical rather than bioprosthetic heart valves prone to inflammation and injury with subsequent rapid deterioration.
Autonomic dysfunction should be considered in patients with sinus tachycardia of unidentifiable aetiology and prior history of chest wall radiation. These patients should be managed as for autonomic dysfunction in the general population, starting with beta blockers. The management of CAD, pericardial diseases, tachyarrhythmia or bradycardia is mostly similar to the rest of the population based on guidelines. The suspicion for constrictive pericarditis should be high in a patient with prior history of chest radiation therapy (particularly prior to the millennium) presenting with cardiovascular complaints.

\section{Prevention and management}

The iron chelator, dexrazoxane, has been consistently shown to aid in the prophylaxis or prevention of anthracyline-induced cardiotoxicity in the past. ${ }^{73}$ This is the only drug approved for preventing anthracycline-related cardiotoxicity; and when used, it is concomitantly administered with anthracyclines. Other prophylactic measures in this setting include the use of liposomal doxorubicin and other anthracycline agents such as epirubicin or anthracycline-like agents such as mitoxantrone, rather than doxorubicin. ${ }^{14}$ More recently, many of the standard heart failure agents (ACE inhibitors/ angiotensin receptor blockers (ARBs) and beta blockers) have shown some promise both in the prevention and in the treatment of chemotherapy-induced cardiotoxicity. ${ }^{74}$ Furthermore, 3-hydroxy-3methylglutaryl-coenzyme A (HMG-CoA) reductase inhibitors (statins) have recently shown reduced cancer-related mortality ${ }^{75}$ and have been associated with more stable LVEF and lower incidence of heart failure. $^{76}$ 
Though not yet validated for reducing radiation-induced heart disease, newer radiation therapy techniques have focused on altering the radiotherapy field and/or avoidance/shielding of the heart in order to reduce excess cardiac irradiation. These are achieved by modulating the dose in surrounding organs with intensity-modulated radiotherapy, DIBH and gated techniques, prone positioning and $3 \mathrm{D}$ conformal radiation therapy. The proton beam technique is purported to offer great potential to minimise cardiovascular events risk by keeping the mean heart dose at $\leq 1 \mathrm{~Gy}^{77}$

Aerobic exercise has been shown to ameliorate doxorubicin-induced cardiotoxicity in animal models, ${ }^{78}$ and reduced the incidence of major CAD and CVD events, as well as heart failure in Hodgkin lymphoma survivors. ${ }^{79}$ As such, prevention is pivotal and should involve weight management, physical activity/exercise and smoking cessation, as well as management of dyslipidaemia, diabetes, hypertension (with the use of ACE inhibitors/ARBs and/or beta blockers), aspirin use and revascularisation as required.

In a study by Hancock and colleagues, a significant proportion of patients who suffered a fatal Myocardial Infarction (MI) because of radiation-induced CAD had no prior symptoms of angina or heart failure. ${ }^{80}$ Unfortunately, there are no accepted guidelines for comprehensive cardiovascular screening of radiation-induced heart disease, and the conundrum lies in the timing, frequency and duration of screening. Future research efforts should aim at better identification of this subset of patients. Certainly, symptomatic evaluation of patients with concerning cardiovascular complaints is warranted.

\section{Main messages}

- With improvements in cancer therapeutics, patients with cancer have improved survival with significant increase in the number of cancer survivors in the last few years; a number that is expected to continue to rise.

- Next to second malignancy, cardiovascular disease (CVD) is the main cause of mortality in cancer survivors, mostly related to long-term adverse cardiovascular effects of cancer therapies.

- Anthracyclines are associated with long-term risk of heart failure even over 20 years after administration of the chemotherapy, particularly when followed by administration of trastuzumab; radiation therapy can cause significant coronary artery disease (CAD), autonomic dysfunction, valvular heart disease, pericardial diseases, tachyarrhythmia or bradycardia years after radiation therapy; cisplatin leads to long-term increased risk of hypertension, metabolic syndrome and cardiovascular events, including MI and stroke.

- Endocrine and hormone therapies usually taken for many years after initial diagnosis of breast and prostate cancers also lead to increased risk of cardiovascular events.

- Awareness of the cardiovascular effects of these agents and appropriate timing of cardiovascular testing, diagnostic assessment of suspected cardiovascular symptomatology, as well as laboratory tests for CVD risk factors in this population are imperative.

- Knowledge of possible preventive measures is important.

- Further research into diagnosis and identification of persons at risk, as well as best CVD preventive measures for this population, is pivotal.

\section{CONCLUSION}

Cancer therapeutics has come a long way towards potentially curing and oftentimes prolonging the life of patients with cancer. As such, the number of cancer survivors in the USA is on the rise. These benefits associated with cancer treatments are sometimes ameliorated by CVD and CVD events as the primary non-malignant cause of death in cancer survivors. Certain chemotherapies, radiation therapy and hormone therapy are associated with CVD in the cancer survivorship years, some lasting more than 20 years after treatment. Knowledge and awareness of these agents and associated cardiovascular risks, as well as diagnosis of CVD and management in these settings, are of utmost importance. It is imperative that the oncology team and the primary care physician work together in the care of the cancer survivor to help detect cancer recurrence as well as monitor for late/long-term effects from acute treatment, including CVD. Prevention of CVD in the first place is even more paramount and referral to cardio-oncology is made based on initial or subsequent risk assessment.

\section{Current research questions}

- Can statins be used to reduce the risk of radiation-induced CAD?

- Is coronary artery calcium a good screening modality for radiation-induced CAD?

- Is hypertension associated with chronic use of bevacizumab reversible?

- Can prophylactic use of an ACE inhibitor or angiotensive receptor blocker just prior to start of bevacizumab therapy be used to prevent proteinuria associated with bevacizumab?

- What is the efficacy of atenolol versus metoprolol or other beta blockers in treating radiation-induced autonomic dysfunction?

\section{Key references}

- Patnaik JL, Byers T, DiGuiseppi C, et al. Cardiovascular disease competes with breast cancer as the leading cause of death for older females diagnosed with breast cancer: a retrospective cohort study. Breast Cancer Res 2011;13:R64.

- Mertens AC, Liu Q, Neglia JP, et al. Cause-specific late mortality among 5-year survivors of childhood cancer: the Childhood Cancer Survivor Study. J Natl Cancer Inst 2008;100:1368-79.

- Cardinale D, Bacchiani G, Beggiato M, et al. Strategies to prevent and treat cardiovascular risk in cancer patients. Semin Oncol 2013;40:186-98.

- Lipshultz SE, Colan SD, Gelber RD, et al. Late cardiac effects of doxorubicin therapy for acute lymphoblastic leukemia in childhood. N Engl J Med 1991;324:808-15.

- Darby SC, McGale P, Taylor CW, et al. Long-term mortality from heart disease and lung cancer after radiotherapy for early breast cancer: prospective cohort study of about 300,000 women in US SEER cancer registries. Lancet Oncol 2005;6:557-65. 


\section{Self assessment questions}

Please answer true $(\mathrm{T})$ or false $(\mathrm{F})$ to the below statement.

1. A 30-year-old woman with a history of breast cancer who had received a cumulative dose of $600 \mathrm{mg} / \mathrm{m}^{2}$ of epirubicin over 6 months is more at risk for chronic anthracycline cardiotoxicity than a 40-year-old man with a history of Hodgkins lymphoma who had received a cumulative dose of $300 \mathrm{mg} / \mathrm{m}^{2}$ of doxorubicin over several years as a teenager.

2. In the list of cardiovascular risk factors such as diabetes, hypertension, dyslipidaemia and cigarette smoking, the most important cardiovascular risk factor contributing to higher risk of chemotherapy-induced cardiomyopathy is hypertension.

3. The risk of radiation-induced cardiac disease begins within the first year and lasts up to 45 years or more after radiation therapy

4. The severity of sinus tachycardia and sinus node dysfunction as a complication of radiation therapy in cancer survivors worsens many years after radiation therapy

5. Apart from anthracyclines, other chemotherapies known to cause cardiomyopathy include monoclonal antibodies, tyrosine kinase inhibitors, proteasome inhibitors and antimetabolites.

Contributors TMO responsible for conception and drafting of manuscript. SA contributed to drafting a section of the manuscript. RR oversaw the drafting of manuscript, cross checked and added references.

Competing interests None declared.

Provenance and peer review Not commissioned; externally peer reviewed.

\section{REFERENCES}

1 American Cancer Society. Cancer treatment and survivorship facts and figures 2014 -2015. Atlanta: American Cancer Society, 2014.

2 Mertens AC, Liu Q, Neglia JP, et al. Cause-specific late mortality among 5-year survivors of childhood cancer: the Childhood Cancer Survivor Study. J Nat/ Cancer Inst 2008; 100:1368-79.

3 Patnaik JL, Byers T, DiGuiseppi C, et al. Cardiovascular disease competes with breast cancer as the leading cause of death for older females diagnosed with breast cancer: a retrospective cohort study. Breast Cancer Res 2011;13:R64.

4 Armstrong GT, Liu Q, Yasui Y, et al. Late mortality among 5-year survivors of childhood cancer: a summary from the Childhood Cancer Survivor Study. J Clin Oncol 2009;27:2328-38.

5 Schindler M, Spycher BD, Ammann RA, et al. Cause-specific long-term mortality in survivors of childhood cancer in Switzerland: a population based study. Int I Cancer 2016;139:322-33.

6 Schultz PN, Beck ML, Stava C, et al. Health profiles in 5836 long-term cancer survivors. Int J Cancer 2003;104:488-95.

7 Oeffinger KC, Mertens AC, Sklar CA, et al. Chronic health conditions in adult survivors of childhood cancer. N Engl J Med 2006;355:1572-82.

8 Menna P, Salvatorelli E, Minotti G. Cardiotoxicity of antitumor drugs. Chem Res Toxicol 2008;21:978-89.

9 Cardinale D, Bacchiani G, Beggiato $M$, et al. Strategies to prevent and treat cardiovascular risk in cancer patients. Semin Oncol 2013;40:186-98.

10 Reulen RC, Winter DL, Frobisher C, et al. Long-term cause-specific mortality among survivors of childhood cancer. JAMA 2010;304:172-9.

11 Swain SM, Whaley FS, Ewer MS. Congestive heart failure in patients treated with doxorubicin: a retrospective analysis of three trials. Cancer 2003;97:2869-79.

12 Steinherz LJ, Steinherz PG, Tan CT, et al. Cardiac toxicity 4 to 20 years after completing anthracycline therapy. JAMA 1991;266:1672-7.

13 Von Hoff DD, Rozencweig M, Layard M, et al. Daunomycin-induced cardiotoxicity in children and adults. A review of 110 cases. Am J Med 1977;62:200-8.

14 Harake D, Franco VI, Henkel JM, et al. Cardiotoxicity in childhood cancer survivors: strategies for prevention and management. Future Cardiol 2012;8:647-70.
15 Lipshultz SE, Colan SD, Gelber RD, et al. Late cardiac effects of doxorubicin therapy for acute lymphoblastic leukemia in childhood. N Engl J Med 1991;324:808-15.

16 Bowles EJ, Wellman R, Feigelson HS, et al. Risk of heart failure in breast cance patients after anthracycline and trastuzumab treatment: a retrospective cohort study. J Natl Cancer Inst 2012;104:1293-305.

17 Ewer MS, Lippman SM. Type II chemotherapy-related cardiac dysfunction: time to recognize a new entity. J Clin Oncol 2005;23:2900-2.

18 Riccio G, Coppola C, Piscopo G, et al. Trastuzumab and target-therapy side effects: is still valid to differentiate anthracycline Type I from Type II cardiomyopathies? Hum Vaccin Immunother 2016;12:1124-31.

19 Ewer SM, Ewer MS. Cardiotoxicity profile of trastuzumab. Drug Saf 2008;31:459-67.

20 Choueiri TK, Mayer EL, Je Y, et al. Congestive heart failure risk in patients with breast cancer treated with bevacizumab. J Clin Oncol 2011;29:632-8.

21 Miller KD, Chap LI, Holmes FA, et al. Randomized phase III trial of capecitabine compared with bevacizumab plus capecitabine in patients with previously treated metastatic breast cancer. J Clin Oncol 2005;23:792-9.

22 Tocchetti CG, Gallucci G, Coppola C, et al. The emerging issue of cardiac dysfunction induced by antineoplastic angiogenesis inhibitors. Eur J Heart Fail 2013;15:482-9.

23 Motzer RJ, Hutson TE, Tomczak $P$, et al. Sunitinib versus interferon alfa in metastatic renal-cell carcinoma. N Engl J Med 2007;356:115-24.

24 Demetri GD, van Oosterom AT, Garrett CR, et al. Efficacy and safety of sunitinib in patients with advanced gastrointestinal stromal tumour after failure of imatinib: a randomised controlled trial. Lancet 2006;368:1329-38.

25 Chu TF, Rupnick MA, Kerkela R, et al. Cardiotoxicity associated with tyrosine kinase inhibitor sunitinib. Lancet 2007;370:2011-19.

26 Haas NB, Manola J, Ky B, et al. Effects of adjuvant sorafenib and sunitinib on cardiac function in renal cell carcinoma patients without overt metastases: results from ASSURE, ECOG 2805. Clin Cancer Res 2015;21:4048-54.

27 Qi WX, Shen Z, Tang LN, et al. Congestive heart failure risk in cancer patients treated with vascular endothelial growth factor tyrosine kinase inhibitors: a systematic review and meta-analysis of 36 clinical trials. Br J Clin Pharmacol 2014;78:748-62.

28 Wells SA Jr, Robinson BG, Gagel RF, et al. Vandetanib in patients with locally advanced or metastatic medullary thyroid cancer: a randomized, double-blind phase III trial. J Clin Oncol 2012;30:134-41.

29 Wilke H, Muro K, Van Cutsem E, et al. Ramucirumab plus paclitaxel versus placebo plus paclitaxel in patients with previously treated advanced gastric or gastro-oesophageal junction adenocarcinoma (RAINBOW): a double-blind, randomised phase 3 trial. Lancet Oncol 2014;15:1224-35.

30 Tabernero J, Yoshino T, Cohn AL, et al. Ramucirumab versus placebo in combination with second-line FOLFIRI in patients with metastatic colorectal carcinoma that progressed during or after first-line therapy with bevacizumab, oxaliplatin, and a fluoropyrimidine (RAISE): a randomised, double-blind, multicentre, phase 3 study. Lancet Oncol 2015;16:499-508.

31 Schmidinger M, Zielinski CC, Vogl UM, et al. Cardiac toxicity of sunitinib and sorafenib in patients with metastatic renal cell carcinoma. J Clin Oncol 2008;26:5204-12.

32 Di Lorenzo G, Autorino R, Bruni G, et al. Cardiovascular toxicity following sunitinib therapy in metastatic renal cell carcinoma: a multicenter analysis. Ann Oncol 2009;20:1535-42.

33 Khakoo AY, Kassiotis CM, Tannir N, et al. Heart failure associated with sunitinib malate: a multitargeted receptor tyrosine kinase inhibitor. Cancer 2008; 112:2500-8.

34 Telli ML, Witteles RM, Fisher GA, et al. Cardiotoxicity associated with the cancer therapeutic agent sunitinib malate. Ann Oncol 2008;19:1613-18.

35 Brouwers $E E$, Huitema $A D$, Beijnen $J H$, et al. Long-term platinum retention after treatment with cisplatin and oxaliplatin. BMC Clin Pharmacol 2008;8:7.

36 Chaudhary UB, Haldas JR. Long-term complications of chemotherapy for germ cell tumours. Drugs 2003;63:1565-77.

37 Haugnes HS, Wethal T, Aass N, et al. Cardiovascular risk factors and morbidity in long-term survivors of testicular cancer: a 20-year follow-up study. J Clin Oncol 2010;28:4649-57.

38 Aydiner A. Meta-analysis of breast cancer outcome and toxicity in adjuvant trials of aromatase inhibitors in postmenopausal women. Breast 2013;22:121-9.

39 Cuzick J, Powles T, Veronesi $U$, et al. Overview of the main outcomes in breast-cancer prevention trials. Lancet 2003;361:296-300.

40 Decensi A, Maisonneuve P, Rotmensz N, et al. Effect of tamoxifen on venous thromboembolic events in a breast cancer prevention trial. Circulation 2005;111:650-6.

41 Nanda A, Chen MH, Braccioforte $\mathrm{MH}$, et al. Hormonal therapy use for prostate cancer and mortality in men with coronary artery disease-induced congestive heart failure or myocardial infarction. JAMA 2009;302:866-73.

42 Nguyen PL, Chen MH, Goldhaber SZ, et al. Coronary revascularization and mortality in men with congestive heart failure or prior myocardial infarction who receive androgen deprivation. Cancer 2011;117:406-13. 
43 Rossari JR, Metzger-Filho O, Paesmans M, et al. Bevacizumab and breast cancer: a meta-analysis of first-line phase III studies and a critical reappraisal of available evidence. J Oncol 2012;2012:417673.

44 Rini BI, Cohen DP, Lu DR, et al. Hypertension as a biomarker of efficacy in patients with metastatic renal cell carcinoma treated with sunitinib. J Natl Cancer Inst 2011;103:763-73.

45 Steingart RM, Bakris GL, Chen HX, et al. Management of cardiac toxicity in patients receiving vascular endothelial growth factor signaling pathway inhibitors. Am Heart J 2012;163:156-63.

46 Nuver J, Smit AJ, Wolffenbuttel BH, et al. The metabolic syndrome and disturbances in hormone levels in long-term survivors of disseminated testicular cancer. J Clin Oncol 2005;23:3718-25.

47 Sagstuen $\mathrm{H}$, Aass N, Fossa SD, et al. Blood pressure and body mass index in long-term survivors of testicular cancer. J Clin Oncol 2005;23:4980-90.

48 Ozkok A, Edelstein CL. Pathophysiology of cisplatin-induced acute kidney injury. Biomed Res Int 2014;2014:967826.

49 van de Velde CJ, Rea D, Seynaeve C, et al. Adjuvant tamoxifen and exemestane in early breast cancer (TEAM): a randomised phase 3 trial. Lancet 2011;377: 321-31.

50 Felicetti F, D'Ascenzo F, Moretti C, et al. Prevalence of cardiovascular risk factors in long-term survivors of childhood cancer: 16 years follow up from a prospective registry. Eur J Prev Cardiol 2015;22:762-70.

51 Meacham LR, Chow EJ, Ness KK, et al. Cardiovascular risk factors in adult survivors of pediatric cancer-a report from the childhood cancer survivor study. Cancer Epidemiol Biomarkers Prev 2010;19:170-81.

52 Meinardi MT, Gietema JA, van der Graaf WT, et al. Cardiovascular morbidity in long-term survivors of metastatic testicular cancer. J Clin Oncol 2000;18:1725-32.

53 Nord C, Fosså SD, Egeland T. Excessive annual BMI increase after chemotherapy among young survivors of testicular cancer. Br J Cancer 2003;88:36-41.

54 Dowsett M, Cuzick J, Ingle J, et al. Meta-analysis of breast cancer outcomes in adjuvant trials of aromatase inhibitors versus tamoxifen. J Clin Oncol 2010;28:509-18

55 Thurlimann B, Keshaviah A, Coates AS, et al., Breast International Group (BIG) 1-98 Collaborative Group. A comparison of letrozole and tamoxifen in postmenopausal women with early breast cancer. N Engl J Med 2005;353:2747-57.

56 Yeh ET, Tong AT, Lenihan DJ, et al. Cardiovascular complications of cancer therapy: diagnosis, pathogenesis, and management. Circulation 2004;109:3122-31.

57 Darby SC, McGale P, Taylor CW, et al. Long-term mortality from heart disease and lung cancer after radiotherapy for early breast cancer: prospective cohort study of about 300,000 women in US SEER cancer registries. Lancet Oncol 2005;6:557-65.

58 Roychoudhuri R, Robinson D, Putcha V, et al. Increased cardiovascular mortality more than fifteen years after radiotherapy for breast cancer: a population-based study. BMC Cancer 2007;7:9.

59 Lancellotti P, Nkomo VT, Badano LP, et al. Expert consensus for multi-modality imaging evaluation of cardiovascular complications of radiotherapy in adults: a report from the European Association of Cardiovascular Imaging and the American Society of Echocardiography. J Am Soc Echocardiogr 2013;26:1013-32.

60 Groarke JD, Tanguturi VK, Hainer J, et al. Abnormal exercise response in long-term survivors of Hodgkin lymphoma treated with thoracic irradiation: evidence of cardiac autonomic dysfunction and impact on outcomes. J Am Coll Cardiol 2015;65:573-83.

61 Darby SC, Ewertz M, Hall P. Ischemic heart disease after breast cancer radiotherapy N Engl J Med 2013;368:2527.

62 Boero IJ, Paravati AJ, Triplett DP, et al. Modern radiation therapy and cardiac outcomes in breast cancer. Int J Radiat Oncol Biol Phys 2016;94:700-8.

63 Plana JC, Galderisi M, Barac A, et al. Expert consensus for multimodality imaging evaluation of adult patients during and after cancer therapy: a report from the American Society of Echocardiography and the European Association of Cardiovascular Imaging. J Am Soc Echocardiogr 2014;27:911-39.

64 Cardinale D, Colombo A, Bacchiani G, et al. Early detection of anthracycline cardiotoxicity and improvement with heart failure therapy. Circulation 2015;131:1981-8.

65 Sawaya H, Sebag IA, Plana JC, et al. Assessment of echocardiography and biomarkers for the extended prediction of cardiotoxicity in patients treated with anthracyclines, taxanes, and trastuzumab. Circ Cardiovasc Imaging 2012:5:596-603.
66 Stoodley PW, Richards DA, Boyd A, et al. Left ventricular systolic function in HER2/ neu negative breast cancer patients treated with anthracycline chemotherapy: a comparative analysis of left ventricular ejection fraction and myocardial strain imaging over 12 months. Eur J Cancer 2013;49:3396-403.

67 Heidenreich PA, Schnittger I, Strauss HW, et al. Screening for coronary artery disease after mediastinal irradiation for Hodgkin's disease. J Clin Oncol 2007;25:43-9.

68 Cardinale D, Colombo A, Lamantia G, et al. Anthracycline-induced cardiomyopathy: clinical relevance and response to pharmacologic therapy. J Am Coll Cardiol 2010;55:213-20.

69 Facemire CS, Nixon AB, Griffiths R, et al. Vascular endothelial growth factor receptor 2 controls blood pressure by regulating nitric oxide synthase expression. Hypertension 2009;54:652-8.

70 Pande A, Lombardo J, Spangenthal E, et al. Hypertension secondary to anti-angiogenic therapy: experience with bevacizumab. Anticancer Res 2007;27:3465-70.

71 Mir 0 , Coriat R, Ropert $S$, et al. Treatment of bevacizumab-induced hypertension by amlodipine. Invest New Drugs 2012;30:702-7.

72 Weintraub NL, Jones WK, Manka D. Understanding radiation-induced vascular disease. J Am Coll Cardiol 2010;55:1237-9.

73 Jones RL. Utility of dexrazoxane for the reduction of anthracycline-induced cardiotoxicity. Expert Rev Cardiovasc Ther 2008;6:1311-17.

74 Bosch X, Rovira M, Sitges M, et al. Enalapril and carvedilol for preventing chemotherapy-induced left ventricular systolic dysfunction in patients with malignant hemopathies: the OVERCOME trial (preventiOn of left Ventricular dysfunction with Enalapril and caRvedilol in patients submitted to intensive ChemOtherapy for the treatment of Malignant hEmopathies). J Am Coll Cardiol 2013;61: 2355-62.

75 Nielsen SF, Nordestgaard BG, Bojesen SE. Statin use and reduced cancer-related mortality. N Engl J Med 2012;367:1792-802.

76 Seicean S, Seicean A, Plana JC, et al. Effect of statin therapy on the risk for incident heart failure in patients with breast cancer receiving anthracycline chemotherapy: an observational clinical cohort study. J Am Coll Cardiol 2012;60:2384-90.

77 Verma V, Shah C, Mehta MP. Clinical outcomes and toxicity of proton radiotherapy for breast cancer. Clin Breast Cancer 2016;16:145-54.

78 Marques-Aleixo I, Santos-Alves E, Mariani D, et al. Physical exercise prior and during treatment reduces sub-chronic doxorubicin-induced mitochondrial toxicity and oxidative stress. Mitochondrion 2015;20:22-33.

79 Jones LW, Liu Q, Armstrong GT, et al. Exercise and risk of major cardiovascular events in adult survivors of childhood Hodgkin lymphoma: a report from the childhood cancer survivor study. J Clin Oncol 2014;32:3643-50.

80 Hancock SL, Tucker MA, Hoppe RT. Factors affecting late mortality from heart disease after treatment of Hodgkin's disease. JAMA 1993;270:1949-55.

81 Heidenreich PA, Hancock SL, Lee BK, et al. Asymptomatic cardiac disease following mediastinal irradiation. J Am Coll Cardiol 2003;42:743-9.

82 Gonzaga AT, Antunes MJ. Post-radiation valvular and coronary artery disease. J Heart Valve Dis 1997:6:219-21.

83 Ong DS, Aertker RA, Clark AN, et al. Radiation-associated valvular heart disease. J Heart Valve Dis 2013;22:883-92.

84 Filopei J, Frishman W. Radiation-induced heart disease. Cardiol Rev 2012;20:184-8.

85 Jaworski C, Mariani JA, Wheeler G, et al. Cardiac complications of thoracic irradiation. J Am Coll Cardiol 2013;61:2319-28.

\section{Answers}

1. $\mathrm{F}$

2. $T$

3. $T$

4. $T$

5. $\mathrm{T}$ 